\title{
On the Importance of Intellectual Property Rights for E-science and the Integrated Health Record
}

Giuseppina D'Agostino

Osgoode Hall Law School of York University, gdagostino@osgoode.yorku.ca

Chris Hinds

Marina Jirotka

Charles Meyer

Source Publication:

Health Informatics Journal. Volume 14, Issue 2 (2008), p. 95.

Follow this and additional works at: https://digitalcommons.osgoode.yorku.ca/scholarly_works

Part of the Health Law and Policy Commons, and the Intellectual Property Law Commons (c) $(i) \Theta \Theta$

This work is licensed under a Creative Commons Attribution-Noncommercial-No Derivative Works 4.0 License.

\section{Recommended Citation}

D'Agostino, Giuseppina et al. "On the Importance of Intellectual Property Rights for E-science and the Integrated Health Record." Health Informatics Journal 14.2 (2008): 95.

This Article is brought to you for free and open access by the Faculty Scholarship at Osgoode Digital Commons. It has been accepted for inclusion in Articles \& Book Chapters by an authorized administrator of Osgoode Digital Commons. 


\title{
On the importance of intellectual property rights for e-science and the integrated health record
}

\author{
Giuseppina D'Agostino, Chris Hinds, Marina Jirotka, \\ Charles Meyer, Tina Piper, Mustafizur Rahman and David Vaver
}

An integrated health record (IHR) that enables clinical data to be shared at a national level has profound implications for medical research. Data that have been useful primarily within a single clinic will instead be free to move rapidly around a national network infrastructure. This raises challenges for technologists, clinical practice, and for the governance of these data. This article considers one specific issue that is currently poorly understood: how intellectual property (IP) relates to the sharing of medical data for research on large-scale electronic networks. Based on an understanding of current practices, this article presents recommendations for the governance of IP in an integrated health record.

\section{Keywords}

eDiaMoND case study, e-health, integrated health record, intellectual property rights, medical databases

\section{Introduction}

The notion that the introduction of new healthcare technologies may necessitate legal clarification is not new. Norris [1], for example, has considered the legal challenges presented by information management technologies in general, and more specifically telemedicine [2] and, with Galpottage, e-consent systems [3]. These studies each highlight the need for the law, and our understandings of it, to evolve in parallel with technologies and the practices that surround them. The complex relationship between medical data, medical practice, and the law has also been the subject of much previous 
research; see for example Lederman's [4] study of data protection in large hospitals. This article is also concerned with medical data, specifically with the intellectual property rights (IPRs) in data, and how they may be particularly relevant to secondary uses of those data.

Our investigations were motivated by a desire to examine these issues as they have emerged in real cases, and thus we orient our discussion in this article around a particular case study. ${ }^{1}$ The eDiaMoND (Digital Mammography National Database) [5] project aimed to develop a federated database of digital mammographic images and patient-related data underpinned by grid technology. The database was created to support breast cancer screening and research nationally. This 2 year interdisciplinary flagship UK e-science project involved a core of 30-50 staff spread over 12 locations, including five universities, four NHS trusts, a global computer firm, and a rapidly expanding university spin-out enterprise. The project received extensive public interest, including articles published by Wired and the BBC, and even a press statement by Prime Minister Tony Blair. The issues discussed and elaborated in this article are derived from a detailed analysis of this project. Key members of the eDiaMoND team were interviewed within the relevant academic, clinical and commercial organizations including managers, researchers, clinicians, and software developers. Project documents were gathered and reviewed to provide an overview of what happened within the project. Contracts were also obtained detailing the legal arrangements and provided a basis for focused legal analysis.

The sharing of patient data is critical to medical research. An essential part of 
our research has been to understand the practices that currently surround secondary uses of medical data. [e.g. 6] Current practices highlight how a level of trust, often based on long-term research relationships, has allowed health services and universities to share data and engage in mutually beneficial collaborations [7]. In addition, collaborations with commercial organizations are of critical importance to medical research. It is quite normal for these collaborations to involve some benefit for the health service department involved such as the provision of state-of-the-art equipment or technical support from the commercial partner. In both situations, medical data are a vital resource that may be employed to ensure maximum benefit for the health service. However, and perhaps unsurprisingly, the ways in which these arrangements are orchestrated are often ad hoc and made on a local basis.

The e-science vision of seamless global sharing of data for research [8] and recent UK NHS initiatives present specific challenges to these current localized arrangements. These innovations raise complex questions relating to ownership and control of the data, and, once ethical obligations have been satisfied, the exploitation of the data for profit. Answers to such questions require invoking IP. A lack of clarity on these issues may potentially lead either to a complete unwillingness to share data, or conversely to costly litigation when conflicting claims come to light; neither is a desirable outcome.

The eDiaMoND project focused on the application of grid technologies within the UK NHS Breast Screening Programme. Central to this vision was an expected shift from film-based to digital mammography technologies. Once 
mammograms were in digital form, it was anticipated that a database would be required to store and manage them. eDiaMoND sought to develop such a database on a national level, and then apply grid technology to manage a series of services to utilize those data. The grid has many potential benefits for digital mammography: radiologists will be able to share images and expertise

in new ways; new grid-enabled computer aided decision algorithms may be developed and used to assist in the reading process; and epidemiologists will be able to draw upon vast stores of accumulated image data for the first time in their cancer research. In order to demonstrate the eDiaMoND vision, it was necessary to obtain a significant quantity of patient data from the clinics collaborating on the project. However, setting up the agreements that led to the acquisition of these data was far from straightforward. In most cases the clinics were keen to participate and willingly contributed data. Nonetheless, one of the clinics requested explicit contractual terms before their data would be released. The negotiations between this clinic, their corresponding partner university, and the coordinating institution, Oxford, took over a year to settle and hence significantly delayed the project's data collection effort. IP rights were of primary concern in these negotiations, and a significant source of confusion. As one team member put it, 'We initially said to [our] lawyers, "Who owns the data?", and they never came back with an answer!' [9]. Thus, the eDiaMoND project is of significant interest, not only because it was considered to be a highprofile project, but also because it presented significant IP management challenges. 


\section{Intellectual property and the value of medical data}

The issue of concern for the clinicians who requested explicit contractual terms before their data would be released was the potential commercial exploitation of the data they were asked to provide. eDiaMoND was a collaboration that consisted of a number of commercial partners, and it was perceived that some of the technologies that they contributed to the project were very close to being products with commercial value. In addition, these clinicians had for a number of years, and through collaboration with their local university, been involved in developing a multimedia tool for the training of radiologists, a key application of the eDiaMoND project (references withheld). The clinicians had provided a substantial corpus of images that formed the basis of the training tool and a number of promising prototypes had already been developed. Becoming a part of the eDiaMoND consortium raised the possibility of substantial benefits as the tool could now be connected to a vast national database of images. However, giving the data to this consortium raised the possibility that the clinic might lose control over them. In particular, the clinics perceived a risk that their data might become part of a commercial training tool that they might then later on be obliged to buy. For the clinicians, the prospect of buying a digital copy of what they perceived to be 'their' data was not acceptable. Such examples provide strong indications of the ways in which clinicians perceive the value for others of the data they capture and use, and their concerns about the effect of collaboration on their own practices. 
Though the case study chosen for this article revolves around an escience initiative, the issue of IP governance is nevertheless of concern to the use of medical data in a wider context. At the time of the project's inception, the technical grid infrastructure of eDiaMoND was considered innovative, but the notion of building databases for medical research is, of course, far from new. The General Practice Research Database (GPRD) is an excellent example. Originally started in 1987, it is now the world's largest computerized database of anonymized longitudinal patient records from general practice, holding data from practices throughout the UK and representing approximately 5 per cent of its population [10]. The size of the database along with the aggregated nature of the data, and the online access that researchers are granted, clearly resonates with the aspirations of the case study presented in this article. Although now managed by the Medicines Control Agency as a not-for-profit operation [11], the project initially started as a commercial enterprise. In its former incarnation as the privately funded Value Added Medical Products (VAMP) Research Database, GPs were offered free computer systems and instruction in exchange for high-quality anonymized patient prescription data. It was a deal that attracted over 2000 general practitioners [12] and further highlights the perceived commercial value of medical data.

More recently, the Icelandic parliament has passed a bill allowing deCODE, a predominantly American funded private company, to obtain a comprehensive electronic database containing health information about the country's entire population, and link this to both genetic and genealogical information [13]. One 
objection to this controversial initiative related to the company's ability to sign exclusive deals with pharmaceutical companies that might prevent other scientists from accessing the data. The deCODE example further reflects both the value that medical data may hold for a range of potential users, and the importance of its governance for research.

IP is an important legal tool for controlling and protecting medical data. In addition, understanding how IP in medical data may be governed is important not just for eDiaMoND research as it moves toward initiating follow-on projects, but also for healthcare research more generally. For example, the CLEF project [14] is seeking to develop a generic framework for research using medical data. In common with the early approach of eDiaMoND, research has not yet begun to address the issue of how IP in the data their systems handle may be governed. The eDiaMOND may be particularly relevant as the CLEF researchers seek industrial partners to continue the development of their platform and begin to deploy professional tools to clinical and academic researchers and the pharmaceuticals industry [15].

On a much grander scale, eDiaMoND foreshadows current projects within the NHS, including Connecting for Health ( $\mathrm{CfH}$ ) in England, which seek both to computerize medical services and to link them at a national level [16]. Within $\mathrm{CfH}$, the initiative of greatest interest, given the topic of this article, is perhaps the Secondary Uses Service (SUS). Whilst initial releases of the SUS focus on providing information for healthcare management such as the Payment by Results (PbR) scheme, future versions are intended to facilitate a kind of medical research that resonates strongly with the e-science vision, giving researchers access to healthcare 
data of an unprecedented range, breadth, and depth. It is widely recognized that good governance of data will be critical to the success of the SUS. However, recent consultations indicate that, at the present time, questions remain, particularly with respect to allowing non-NHS organizations to access the database and determining ways in which this access should be governed [17].

The following section details the main legal issues that were identified as relevant and consequential to our understanding of IP in the eDiaMoND project. Once the main issues in law have been described, we then detail the ways in which such laws may apply to the specific practices that shaped the eDiaMoND collaborations. From this analysis, we produce some specific recommendations as to the governance of IP in e-science projects and an integrated health record.

\section{Legal background}

It is perhaps not surprising that, by and large, many researchers, participants in projects and the public at large are unfamiliar with the ways in which IP relates to medical data [18]. Issues relating to IP rights over data and databases and control over data are complex and often decided on precedent. Throughout the course of our investigations, it became clear that there was a fundamental lack of understanding and in some cases misunderstanding by nonspecialists of IP law, and of law more generally. In many cases, academics, researchers, engineers and administrators did not fully appreciate that medical data could even be subject to IP, much less that there may be various ways in 
which this might occur. In addition, there was a recurring perception that IP was obstructive to research, something that we needed to 'get rid of' rather than a means of protecting individuals and organizations. These perceptions sit in sharp contrast to the reality that IP cannot be eliminated unless explicitly assigned or effectively 'donated' to the public.

The following sections summarize the most relevant legal concerns to the questions that emerged from the eDiaMoND case study. The main legal issues examined were copyright, database and other rights in the mammograms (MMRs) and in the software. Whilst we recognized the importance and interplay of ethical, confidentiality, data access and privacy concerns, we do not directly address these issues here. The interaction between all these factors is extremely complex and this project starts to unravel this complexity by focusing explicitly on IP ownership questions in the UK. On these issues, other jurisdictions have been consulted for comparative purposes. ${ }^{2}$

\section{Copyright law}

A key objective of copyright is to grant exploitation rights to owners of original works. Thus, under the UK Copyright, Designs and Patents Act 1988 (CDPA), ${ }^{3}$ copyright initially grants various enumerated exploitation rights to the 'author' who 'creates' a work. ${ }^{4}$ That work must meet the legal standard of 'originality'. ${ }^{5}$ The test for a work's originality is a matter of degree depending on the amount of skill, judgement, or labour involved in its making. ${ }^{6}$ Consequently, not only must creative intellectual activity produce the right kind of work, but the 
author's input must satisfy a certain minimum standard of effort' ${ }^{7}$ The author is an individual who is solely responsible and exclusively deserving of the credit for the creation of a work. ${ }^{8}$ The CDPA grants protection to a number of categories of works. For instance, a literary work is defined in the CDPA as a written work, other than dramatic or musical, that may include computer programs or compilations.

\section{Determining copyright ownership}

The first owner of copyright is typically the creator, but there are exceptions. One of the main exceptions particularly relevant to the eDiaMoND case study deals with employees. Whilst independent contractors retain copyright over their works (unless an express or implied contract provides otherwise), employees' copyright ownership of their works resides with their employers pursuant to the 'course of employment' doctrine. ${ }^{9}$ Contract law governs the management of copyrights. In the UK, the CDPA governs copyright transfers and licences. A licence may be express, oral or implied by conduct and may be exclusive or nonexclusive. Similar in scope to assignments, ${ }^{10}$ exclusive licences must be in writing authorizing the licensee to exercise a right to the exclusion of all other persons including the licensor. ${ }^{11}$ Non-exclusive licences imply that other licensees may be appointed to compete with one another and the independent contractor..$^{12}$ It also means that, in contrast to assignments that transfer ownership, the independent contractors retain the right to exclude everyone other than the licensees from use of their works. ${ }^{13}$ Licences can be limited by time, scope, use and duration. Assignments and licences can be partial. For example, independent contractors may license only 
print rights. In the UK, future copyright can be assigned, ${ }^{14}$ thereby vesting copyright in the assignee once the future work comes into existence. Moral rights can be waived in writing but cannot be assigned. ${ }^{15}$ So if independent contractors intend to grant assignments or exclusive licences, these must be in writing.

\section{Database law}

European databases are governed by a complex legal regime. The EC Database Directive ${ }^{16}$ provides the most comprehensive legal protection of databases. Its provisions have been implemented and modified in the UK by the Database Regulations. ${ }^{17}$ Two other legal instruments also apply to databases: the UK Copyright, Designs and Patents Act in s. 3A, and Article 5 of the World Intellectual Property Organization (WIPO) Copyright Treaty. The Database Directive and UK Regulations most directly apply to the eDiaMoND database.

There are three tiers of substantive legal protection of databases in IP law: (1) the database itself is protected by copyright; (2) the investment in databases is guarded by the database right; and (3) the contents of the database may be protected by copyright or other IPRs (such as patents, trademarks etc.). This last ground was discussed above; the first two will be addressed in turn.

The UK Regulations define a database as 'a collection of independent works, data or other materials which (a) are arranged in a systematic or methodical way, and (b) are individually accessible by electronic or other means'. ${ }^{18}$ The Explanatory Memorandum describes the contents of the database as "information" in the widest sense of that term' and this definition of a database has recently 
been explored by the European Court of Justice. ${ }^{19}$

The creator of a database is also protected against unauthorized extraction or utilization from the database by the so-called sui generis data-base right in the Database Directive. Its protections have been imported and modified in UK law by the UK Database Regulations and were recently extensively addressed by the European Court of Justice. ${ }^{20}$

The database right belongs to the person who takes the initiative and assumes the risk in investing in obtaining, verifying or presenting the contents of a database..$^{21}$ That investment must be substantial in a quantitative and qualitative sense, and cannot be in the creation of the data but is rather in its collection into the database. ${ }^{22}$ Employees are excluded from the right unless their inclusion is specified by contract. ${ }^{23}$ The right can be held jointly and by many people. It protects against substantial extraction or reutilization of all or a substantial part of the database without consent. ${ }^{24}$ The term of the database right is 15 years from the date when the database was completed, but any substantial change to the contents of a database qualifies the resulting database for its own term of protection. ${ }^{25}$ The database right also allows a right of fair dealing with the database for research for non-commercial purposes.

In the following section we describe our analysis of the eDiaMoND project, the ways in which these laws impact upon the collaborations within the project and the corresponding implications for the eDiaMoND data. 


\section{Analysis of eDiaMoND}

\section{Methodological approach}

The IMaGE project was a 1 year collaboration between lawyers, social scientists and software engineers. This consortium of researchers came together in order to understand and evaluate current IP law and social practice. In addition, we sought to develop recommendations for policy regarding alternative ways in which the law might operate in the future. As stated previously, in order to understand how these issues emerged in practice, we conducted a retrospective study of the eDiaMoND project. By surveying the applicable IP laws, our analysis attempted to determine where, and in what artefacts of eDiaMoND, IP could be seen to reside. And more importantly, who, for the purposes of the law, should own the IP? These legal findings were then applied to the actual practices from the case study to uncover who 'in reality' owned and controlled the IP in eDiaMoND. As our findings indicate, who owned the IP in practice did not mirror who legally owned the IP. We also identified potential difficulties with the contractual arrangements of the project.

Our methodological approach evolved in three phases. In the first phase, we conducted a retrospective study of the eDiaMoND project by analyzing documents produced by the project combined with unstructured interviews with key members of the eDiaMoND team and its stakeholders. These materials provided the background to the project and its aims; a sense of the challenges that members of the project faced; and a catalogue of the agreements that were 
reached during the project between its partners. In parallel, a thorough review of relevant jurisprudential research relating to the ownership (IP) rights was conducted. ${ }^{26}$ The second phase focused on the development and evaluation of various models for the ownership of IP rights in such data. The final phase disseminated our findings, after which we re-evaluated our models from the feedback. In addition, the IMaGE team analysed the viability of technical controls that complemented methods of legal regulation, e.g. technology protection measures (TPMs) that could be employed as a means of digital rights management (DRM) to ensure that IPRs in digitized mammograms are preserved and controlled in compliance with the law. Space prohibits a thorough description of this research in this article, but see [19].

\section{eDiaMoND practices around data acquisition and contractual}

\section{agreements}

In order to fulfil the aims and objectives of the project, the eDiaMoND consortium acquired some 1600 digital mammograms and patient-related information from four clinics. As IP was central to the negotiations of the collaborators involved, our analysis focused on the process of data acquisition and the agreements that were forged to facilitate it. Once ethical clearance had been given, the necessary images and patient-related data information were obtained from clinics via a university intermediary who then liaised with Oxford to upload the data into the project's database. The commercial partners provided the technology to acquire data and place the data in standardized form on the grid. 
The mammograms used included those already pre-selected for training or epidemiological purposes in addition to those taken directly from patients in the clinic. The majority of mammograms were film-based X-rays. Patient records were generally on paper. Thus, much of the effort of acquisition was expended on the scanning and data entry that was necessary to digitize the data. However, a number of cases were taken directly from digital equipment. This complex process of data collection and use is critical in considering the IP rights involved.

As a result of the numerous participants, the sensitive data and the technology implicated, the parties concluded agreements to manage the expectations and interests of the various clinical, research and commercial interests in the IP of the images involved. More often than not, agreements were made orally, rather than in writing. In some cases, no explicit allocation of IPRs was discussed or reached. The project partners exhibited significant uncertainty as to 'who owned what images' at the end of the project. At the top level, eDiaMoND was based on a three-way collaboration agreement between Oxford and the two major commercial partners. This agreement clarified, for example, what would happen to any IP that was developed in the form of software during the project. However, it made no mention of medical data. The data were to come from the participating clinics. Each of these clinics, in collaboration with their individual university partner, was to acquire data and upload them into the project's grid database. Unlike the main collaboration agreement, the relationships between each participating university and their clinic, and between those universities and Oxford, were ad hoc, and in some cases quite informal. As 
the following will describe, this makes ownership of those data much harder to define.

\section{eDiaMoNDownership rights}

Ownership rights among trusts and universities. The IMaGE project examined the ownership right in MMRs as artistic works and the data and software as literary works. An individual MMR may have three types of copyright attached: copyright in the actual image, copyright in the annotations, and copyright in the entire record. Copyright is also vested in eDiaMoND's entire database of mammogram data, whether textual or in image form. Copyright ownership in each may vary depending on the general rules of copyright. ${ }^{27}$

In eDiaMoND, the trusts have been found to retain copyright over the original images and possibly the digitized images. This ownership has been vested in two different ways:

(1) by express agreement and (2) by implied licence. The first case of express agreement was less common: only in one trust-university relationship (Clinic 1 and University 1, respectively) was IP ownership specified. A clause in the agreement clearly specified that the data be retained by Clinic 1 with University 1 enjoying use rights for the eDiaMoND project only. ${ }^{28}$ In the case of the other three trust-university relationships there was an implied licence between the parties, based on the absence of a written contract and the exchange of communications between the parties. As independent contractors, the trusts retain the data because they are the creators of the data. So despite the lack of a contract, ownership rights 
can still be implied. Even so, the exact scope of this licence is unclear (e.g. whether the data can be used for commercial purposes or for other non-commercial purposes). Going forward with more certainty in ascribing ownership rights is necessary.

Ownership rights among radiographers and others. Most of the radiographers or technicians who scanned and/or annotated the images were employees of the trusts. As such, all IP generated by them belongs to the trusts due to the absence of a formal contractual agreement. However, several technicians were not employees but independent contractors; such status raised ownership concerns. For instance, in the relationship between Clinic 1 and University 1 , despite the contractual certainty in the flow of IP rights among these entities, the work of an independent clinical assistant who scanned images supplied by Clinic 1 and entered data from clinical records for University 1 raised ambiguity. The clinical assistant was paid by University 1 but worked at Clinic 1, and although she was bound by an honorary contract with the clinic, the contract made no explicit mention of IPRs. ${ }^{29}$ The data generated can therefore be owned either by the assistant as an independent contractor or by the university. This would be a perverse result for the future of such a project as eDiaMoND, as the expectation among the parties, and the NHS, is that the data are to be retained by the trust. ${ }^{30}$ Uncertainty in these rights could result in an incomplete database. Any future use of the eDiaMoND data generated by the radiographer and the IP in such data would require permission (and it is uncertain who would be in a position to 
authorize this use).

The eDiaMoND project used a number of independent contractors, particularly for data acquisition. However, there are also potential concerns relating to permanent employees. Consider the case of a research assistant at University 2 who obtained digitized images from Clinic 2, and then entered various pieces of patient data. According to NHS policy, ${ }^{31}$ when medical research and development are conducted in partnership with industry or universities, the partners should, where possible, agree IP arrangements in advance. The fact that this was not done makes it likely that the data in this case are owned either by the research associate, or by University 2, another perverse conclusion. The important assumption here is that these workers (the research assistant, the radiographer, or the clinical assistant) did create original works to attract copyright protection..$^{32}$ In the case of the radiographer, a case for copyright protection is more easily made because of her exercise of skill and judgement, though arguably the same holds for the others who acted similarly. ${ }^{33}$

Ownership rights in software. Software ownership does not raise any major concerns as Oxford and the participating software companies had concluded a collaboration agreement. The companies jointly own any software developed for eDiaMoND. Oxford has a perpetual non-exclusive licence to use software for non-commercial purposes. This may become problematic should Oxford decide to use the same software application for commercial purposes. Similarly, the software companies may not necessarily enjoy the rights to use the 
MMR data to train and test implementations.

\section{Copyright in databases}

Databases are protected by copyright if they are the author's 'own intellectual creation' ${ }^{34}$ The creativity required for protection is in the selection and/or arrangement of the contents of the database..$^{35}$ Copyright protection of the database requires a relatively high standard of originality. The author holds the right and it protects rights of reproduction, distribution and making available to the public.

Whilst the issue of whether the various databases in general qualify as a 'literary work' remains an open question, we can draw preliminary conclusions about copyright that may be held by various project stakeholders. Clinic 1 and Clinic 3 both contributed pre-existing local databases to the eDiaMoND project. They had already selected various typical images for teaching purposes and had arranged those images according to their internal filing system. These databases would likely meet the threshold for copyright protection. The other clinics assembled their local databases by choosing patients in the waiting room who consented to the use of their images for the purposes of eDiaMoND. This level of selection and arrangement less convincingly meets the threshold for copyright protection. The eDiaMoND project, in the creation of a database incorporating the databases of the participating trusts, delegated selection of database elements to the local trusts. eDiaMoND coordinated the scanning, sorting of information fields and overall layout of the data in the database and would, thus, meet the standard of 'arrangement'. Consequently, the larger database as well as some of the 
participant databases would likely be subject to both eDiaMoND and participant claims to copyright over the databases.

\section{Conclusion on copyright ownership}

The trusts own the IP in the original images and likely in the digital images. This results from an implied licence or, in the case of Clinic 1, through an explicit licence in the form of a contract. Both approaches provided the same short-term results. The universities were able to use the data for the eDiaMoND project, and the trusts, in turn, expected to retain the rights to the data. However, in the longer term, more legal certainty is necessary for the success of e-science and the vision of sharing and reuse of medical data in general. This uncertainty becomes pressing particularly when considering independent contractors who may have ownership rights in the data generated. NHS policy, which arguably mandates that ownership of medical data is vested in the trust, would not support such a result. Lastly, eDiaMoND project participants collectively retain use rights in the images for the duration of the programme but do not have reuse rights from either an IP or an ethical clearance perspective. Even if ethical clearance was granted for a follow-on piece of research, a lack of IP clarity could lead to undesirable consequences. This concern applies not only to the eDiaMoND project specifically, but also to e-science projects more generally.

\section{Conclusionon database ownership}


The parties involved in the eDiaMoND project did not turn their attention to the ownership of databases when they were planning the project. This is evident from the documentary and interview research conducted. This means that the state of IP held in the databases is uncertain and has stalled future sharing and further technical exploitation of the existing databases. Some trusts have a strong claim to copyright and database rights in their databases due to their pre-existing collection activities. The creators of the eDiaMoND database are also likely to have copyright and database rights in the databases of mammogram images. It is interesting to note that the database right is not well tailored to the case of a mixed public and privately funded initiative. The database right in this case also highlights the intersection between the originality requirement for copyright and the legal criteria of the database right.

\section{The eDiaMoND database and database rights}

The eDiaMoND collection, as well as some of the pre-existing databases held by the trusts, fall under the legal definition of database..$^{36}$ They are collections of images that are separable from one another without affecting their value and have been systematically or methodically arranged to be independently accessible from a fixed hardcopy or electronic base. ${ }^{37}$ In the eDiaMoND project, clinics 1 and 3 took particular efforts to create their pre-existing collections by selecting representative MMRs, verifying the accuracy of the MMRs and their use as typical cases, and presenting them in the database according to their internal filing system. Clinics 2 and 4, however, have a weaker claim to database 
protection over their pre-existing collections since those collections were largely incidental to the creation of data, as discussed previously. Thus, some of the trusts have a stronger claim to rights in their databases than others. In terms of the larger eDiaMoND database, a range of organizations took the initiative and assumed the risk in investing in and obtaining data in database form, through coordinating standardized annotation and scanning, as well as verifying and presenting the contents of the database. In particular, a global computer firm, Engineering and Physical Sciences Research Council (EPSRC), the Department for Business, Enterprise and Regulatory Reform (formerly the DTI) and the Medical Research Council (MRC) made the most financially significant investments, although questions may remain over the threshold for finding 'substantial investment' ${ }^{38}$ The core eDiaMoND team at the University of Oxford and its commercial spin-out partner undertook the most substantial investment and initiative in obtaining and verifying data. The legitimate claims to eDiaMoND by commercial and government partners over a database of sensitive medical information highlights an area of potential legal and ethical conflict.

\section{General conclusions}

Our research concludes that trusts likely own and control the IP in MMRs in these types of large-scale collaborative projects in the medical sector. This arrangement should be clarified at the onset by explicit agreement; additional concerns relating to patient confidentiality and ownership of their data must also be addressed. A legally clear situation may be preferable to one where the legal rights 
are determined ad hoc, after the fact, or during a formal legal dispute. Once ethical considerations have been satisfied, without a clear notion of IP ownership it is impossible to know who has the authority to approve new research, or indeed who should benefit from any subsequent commercial exploitation. These questions hold the potential to severely challenge the concept of seamless data sharing that is so critical to the e-science vision and the integrated health record.

\section{Governance of IP ownership}

A key objective of the IMaGE project was to develop and then assess models that managed the ownership of IPRs associated with collaborative databases of medical images and associated textual data. It was hoped that such models of IP would provide more clarity for future e-health initiatives such as the IHR, and stimulate debate as to how IP should govern ownership of digitized medical data. Based on the findings from our investigations, we examined three distinct conceptual models of potential IP governance of digitized medical data for secondary uses: (1) NHS trust centred, (2) patient centred, and (3) a national ownership model. Trust governance 
Our research suggested that the most common expectation amongst the parties was that the IP in a patient record was vested in the trust from whom the patient received treatment or a diagnosis, subject to a patient's limited control over the data. The scope of the patient's control would be defined mainly through the patient's statutory rights in her medical records. This model therefore recommends maintaining the status quo of trusts retaining local control and responsibility for protecting data as deemed owner of the IP. However, the situation would be clarified by a policy document for all trusts specifying the permitted uses of the IP in the data. Under this model the trusts would remain one of the beneficiaries of any databases created using their data. Further, standard clauses would be developed allowing, for example, non-exclusive rights in other trusts to access the data for research, diagnosis and treatment purposes and granting the NHS a worldwide, irrevocable, royalty-free licence for its own non-commercial purposes. Researchers would negotiate with each individual trust to obtain the required set of data as is currently done. However, more ambitious variation would see trusts adopt an open access approach, implemented through creative commons or public licence type contracts.

\section{Patient-centred governance}

A radically different model would allow patients to own the IP in their medical record. Currently, while patients have statutory rights to access and control uses of their data, they do not hold any copyright or database rights in their records. Contracts between all parties could be standardized to assign all IP to the 
patients. Similarly, legislative amendments could vest all IP in the context of medical data to patients. As in the music industry, a collecting organization could be established to manage patients' new rights and act as a conduit. Patients could then receive royalties based on the uses of their data. Patients could opt to waive their rights to remuneration in all cases or in some (e.g. collect money for commercial uses of data), or manage them through 'open source' licensing arrangements (as discussed above). Through compulsory licensing, patients could be obliged to license their data. A tribunal could set tariff amounts and resolve any disputes.

\section{National governance}

The third model proposes to assign IP rights in the medical record to a central organization (or, for example, to the Secretary of State for Health). This would be similar to the kind of national database proposed by 'Connecting for Health'. Medical records could be created as the result of clinicians' work at multiple NHS trusts, researchers might draw on records originating all over the country, and the exploitation of these records could then be handled by a single national body. In cases where clinicians have established their own collections of records for research or training purposes, the exploitation of such collections can be protected by the database right. It may be possible to implement this model using contracts; however, a more compelling alternative would be 
legislative reform, where for example a sui generis law on medical data in research collaborations could vest ownership in a national body. Alternatively, legislation could be enacted to provide a limited exception to infringement in the UK Copyright, Designs and Patents Act 1988 (e.g. in the form of fair dealing or for use of the work for purely educational or research purposes).

\section{Analysis of the governance models}

Our approach to and conclusions about the evaluation of these models combines our own understandings of existing policies, for example of IP in the NHS, and consultation with a wider group ${ }^{39}$ at workshops we hosted and attended.

The first model best serves the needs of e-health collaborators in the short term as it supports and clarifies the current system of trust that exists among researchers, without significantly changing the way the research community currently views IP ownership. It does not require legislative change, and it colocates data and IP control in the trusts. Disadvantages are that it could undesirably relegate responsibilities to inexperienced administrators and researchers and ineffectively address the fragmentation of approaches across projects and regions. The first model's approach would not be successful if standard clauses are not developed and used by collaborators to make the rights allocations abundantly clear at the point at which a project is initiated.

The second model allows collection of and access to vast quantities of data whilst patients retain IP ownership interests. Incidentally, this model could provide 
accountability to patients for use of their data. However, granting patients ownership rights may be problematic as it: (1) runs contrary to the default state of the law; (2) may make it more difficult to establish research projects with commercial partners; (3) is highly ambitious and may be cumbersome to implement; and most importantly, (4) runs contrary to NHS policy on the exploitation of IP. Indeed, the very idea of patients potentially making money from their data in a public healthcare system seems undesirable. Additionally, some patients have suggested that ownership is not needed provided there remain sufficient safeguards in the law to regulate the use and dissemination of such data, and in particular to ensure that the data remain sufficiently anonymized.

The main disadvantage of the third model is that although legislative reform may be more effective and result in a larger data repository, especially in the longer term, legislative reform is time-consuming and difficult to attain. Consequently, such an approach will require more careful study.

\section{Conclusion}

This analysis of the ways in which contractual arrangements were forged within the eDiaMoND project, coupled with our understanding of the practices of data acquisition and the current state of IP law, have enabled the project to make some specific recommendations for future research into the sharing of medical data in such projects and data reuse. For example, independent contractors were employed to work on the data collection, 
primarily to scan and/or annotate images. This resulted in some uncertainty and thus potential problems for the trusts as to where the IP may lie. If not explicitly expressed, a default position may result in copyright residing with the independent contractor. This would suggest that honorary contracts should be more specific and include IP arrangements. Such contracts could, and arguably should, include clauses clarifying that the trusts retain copyright in the independent contractor's works on behalf of the trust. Such an approach may encourage researchers at universities and clinics to consider the data used and generated as valuable assets that are best exploited with clear contractual provisions regarding ownership of the IP. In terms of the governance models it seems that the trust governance model is the most feasible to implement in the short term. This readily serves the needs of the rapidly developing e-health systems, many of which are currently affected by the lack of clarity and guidance. However, it is also crucial that the NHS, working with the medical and research communities, raise awareness on the importance of IP, evaluate the potential of standardizing IP clauses, and address basic technological measures that must be implemented in order to support the model. This is a timely opportunity as the National Programme for IT (NPfIT) is being deployed across England. A slightly modified version may designate regional hubs to allow small variations to be enacted to suit local needs. However, a longer-term and a more permanent solution would be to move towards national governance. But this would, as noted, necessitate time-consuming legislative reforms requiring further research into IP, consultation with the research community and open debates involving the public at large. 
Electronic health records will allow individuals to share medical data across numerous organizations in increasingly dispersed geographical locations. This continues to raise new copyright and data protection challenges. Greater certainty in this rapidly changing landscape is crucial for the ongoing success of pioneering projects like eDiaMoND. Good governance of SUS will be critical for future e-health systems. Additionally, we need to understand the interplay between IP and ethical issues as well privacy, property, confidentiality and consent in order to enable advances and innovations in the medical field that may ultimately improve healthcare.

\section{Notes} entitled 'IMaGE

1 This research was supported by the ESRC as part of the e-Society Programme project

- Intellectual Property Rights in Medical Databases for a Grid Environment', under grant number ESRC RES-341-25-0033, 2005-6.

2 Note that the IMaGE project does not focus on physical ownership issues (e.g. which entity is best able to store the physical boxes of data); the focus is on the intangible aspect of such property, the IP.

3 Copyright, Designs and Patents Act 1988 c. 48 as amended.

4 CDPA s. 2 (1) exploitation rights delineated further in Part II. For comparative purposes to Canada's Copyright Act RSC 1985 c. C-42 ('CCA') s. 3, copyright means the sole right to reproduce, perform or publish a work and procure any profits therefrom.

5 University of London Press Ltd v. University Tutorial Press Ltd [1916] 2 Ch 601, 608: 'the Act does not require that the expression must be in an original or novel form, but that the work must not be copied from another work - that it should originate from the author'. Or as J. Litman The Public

Domain (1990) 39 Emory L. J. 965-1023, 1000 states, originality is used for dividing works 'privatelyowned from the commons and to draw lines among the various parcels of private ownership'.

There are various views on the subject that elide clear definitions.

6 W. R. Cornish Intellectual Property (5th edn Sweet \& Maxwell London 2003) 388; $\mathrm{CCH} v$ Law Society of Upper Canada [2004] 1 SCR 339: 'What is required to attract copyright protection in the

expression of an idea is an exercise of skill and judgment.' See also Slumber-Magic Adjustable Bed Co v Sleep-King Adjustable Bed Co and others [1984] 3 CPR (3d) 81 (BCSC).

7 W. R. Cornish Intellectual Property (5th edn Sweet \& Maxwell London 2003) 388; Ladbroke (Football) Ltd $v$ William Hill (Football) Ltd [1964] 1 All ER 465 (HL).

8 M. Woodmansee 'The Genius and the Copyright: Economic and Legal Conditions of the Emergence of the "Author"'. Eighteenth-Century Studies 425-48, 426.

9 CDPA s. 11 (2); in Canada, Copyright Act RSC 1985 c. C-42 s. 13 (3); in the US, 
Copyright Act 197617 USC s. 101 'works made for hire'.

The distinction between licences and assignments 'is not always so clear-cut'; an exclusive licence of all rights to run until the rights expire is in practical effect like an assignment. And so, 'it is not so

much what the contract is called but the effect of the transaction which decides whether there is an assignment or a licence'. H. Pearson and C. Miller Commercial Exploitation of Intellectual Property (Blackstone Press, London 1990) 344.

11 CDPA s. 92 (1).

12 D. Vaver Copyright Law (Irwin Law, Toronto 2000) 238.

13 Pearson and Miller (n. 14) 343.

14 CDPA s. 91.

15 CDPA ss $94-95$.

16 Directive 96/9/EC of the European Parliament and the Council of 11 March 1996 on the legal protection of databases.

17 Copyright and Rights in Databases Regulations 1997 (SI 1997 no. 3032).

18 Reg. 6.

19 Fixtures Marketing Ltd v. Organismos Prognostikon Agonon Podosfairon AE (OPAP) [2004] ECR I-10549.

$20 \quad$ Fixtures Marketing v. Svenska AB C-338/02; OPAP (n. 39); Fixtures Marketing Ltd. v. Oy Veikkaus $A b$

C-46/02; British Horseracing Board Ltd v. William Hill Organization Ltd C-203/02 (BHB).

21 Reg. 14 (1).

22 BHB (n. 42).

23 Reg. 14 (2).

24 Reg. 16 (1).

25 Reg. 17 (3).

$26 \quad$ Note that it was beyond the remit of the IMaGE project to address conflicts between individual rights and collective demands, as these are resolved through confidentiality, privacy and data protection law. The IMaGE project instead focused on the intellectual property legal regime and the behaviour in practise of the stakeholders in such regime as it applies to shared medical data.

27 Despite these differences, copyright persists for 70 years from the time of first fixation.

28 All IP arising from the performance of the work by [Clinic 1] for the purpose of the eDiaMoND project shall remain vested in [Clinic 1]. [University 1] shall procure that [Clinic 1] shall grant a licence to [University 1] and [University 1] shall grant a paid up licence to Oxford so that each of [University 1] and Oxford shall have the right to use the mammograms (including any adaptation thereof), and other data for the purposes of the eDiaMoND project (which for the avoidance of doubt shall include a right to make the same available to any other eDiaMoND project participant for such purpose only).

29 The actual contract was not available to us; however similar honorary contracts from this NHS trust make no mention of IP.

30 See Department of Health, 'NHS Framework and Guidance on the Management of IP in the NHS', http://www.innovations.nhs.uk/pdfs/77169_doh_nhsnnovative_orgfinal.pdf>, UK, September 2002 (took effect 9 September 2002 along with Health and Social Care Act 2001).

31 lbid. 67-9.

32 The mere mechanical act of transforming a work from analogue to digital format may not constitute an original work and may in fact attract copyright infringement; see in the US Tasini v New York Times 533 US 483, 121 S Ct 2381 (2001).

33 For example, even what initially seemed like straightforward data entry required some skill, requiring the assistant to rearrange a given set of clinical data fields so that 
they may be entered into the 'unified' scheme required by the eDiaMoND database. Thus it was important so that the assistant was able to read and understand the clinic's original medical records.

34 Database Directive, Article 3.

$35 \quad$ Article 3 (1).

$36 \quad$ Note that the database right does not protect the computer software driving the database: Article 1 (3). Computer programs are protected independently by the European Software Directive of 1991: Council Directive $91 / 250$ on the legal protection of computer programs, OJ L 122/42 of 17 May 1991.

37 Ibid. nn 29-36.

38 Due to space constraints only an overview of the contributions is provided.

This group comprised a range of stakeholders including those from the NHS, medical law practitioners, technology developers and researchers, medical researchers and patents advisers.

\section{References}

1 Norris A C. Essentials of Telemedicine and Telecare. Chichester: Wiley, 2002. Journal 2002;

2 Norris A C. Current trends and challenges in health informatics. Health Informatics

8 (4); 205-13.

3 Galpottage P A B, Norris A C. Patient consent principles and guidelines for econsent: a New Zealand perspective. Health Informatics Journal 2005; 11 (1); 5-18.

4 Lederman R. Managing hospital databases: can large hospitals really protect patient data? Health Informatics Journal 2005; 11 (3); 201-10.

5 www.ediamond.ox.ac.uk.

6 Jirotka M, Procter R, Hartswood M, Slack R, Simpson A, Coopmans C, Hinds C. Collaboration and trust in healthcare innovation: the eDiaMoND case study. Journal of Computer Supported Cooperative Work 2005; 14 (4); 369-98.

7 Hinds C, Jirotka M, Rahman M, D’Agostino G, Meyer C, Piper T, Vaver D. Ownership of intellectual property rights in medical data in collaborative computing environments. In First International Conference on e-Social Science, Manchester, UK, June 2005.

8 Taylor P. Presentation given at UK e-Science Meeting, London, July 2001.

9 Interview 050317: 1400-292.

10 Mann R D, Andrews E B. Pharmacovigilance. Chichester: Wiley, 2002.

11 Yamey, G. Medicines Control Agency takes over GP research database. British Medical Journal 1999;

319 (30 October); 1153.

12 Handysides, S. Enriching careers in general practice: new roles for general practitioners. British Medical Journal 1994; 308 (19 February); 513-16.

13 Anderson R. The DeCODE Proposal for an Icelandic Health Database. 1998.

14 http://www.clef-user.com/index.html.

15 http://www.clef-user.com/page6.html.

16 http://www.connectingforhealth.nhs.uk/.

17 http://www.connectingforhealth.nhs.uk/sus/engagement.

18 Vaver D. Does the public understand intellectual property law? Do lawyers? Keynote address, Meredith Memorial Lectures, McGill Law School, 17 March 2006.

19 Rahman M. Securing IPR in e-health. MSc thesis, Software Engineering, Oxford University, UK, 2006. 
Correspondence to: Marina Jirotka

\section{Giuseppina D'Agostino}

DPhil; Barrister and Solicitor of the Bar of Ontario 2001 Call; Assistant Professor of Law, Osgoode Hall Law School of York University

Chris Hinds BSc MSc, DPhil research student

Oxford University Computing Laboratory, Wolfson Building, Parks Rd,

Oxford OX1 3QD, UK

Tel: 44 (0)1865 283738, 44

(0)1865 283739

Marina Jirotka BSc MA

DPhil; Lecturer, Oxford University; Associate Director, Oxford eResearch Centre

7 Keble Road, Oxford OX1 3QG, UK Tel: 44 (0)1865 610613

Fax: $44(0) 1865610612$

Charles Meyer BS Systems Engineering MS Operations Research Juris Doctor BCL; licensed to practise law in Ohio and Maryland; Visiting Assistant Professor of Law (2006-7) at the University of Houston
Tina Piper BASc LLB BCL MPhil; Assistant Professor, Centre for Intellectual Property Policy, McGill Faculty of Law

3644 Peel Street, Montreal QC,

Canada H3A 1 W9

Tel: 5143984324

Fax: 5143983233

E-mail: tina.piper@mcgill.ca.

Mustafizur Rahman BSc MSc, Programme Manager, Oxford University

oU Begbroke Science Park, Sandy Lane, Yarnton, Kidlington OX5 1PF, UK

Tel: 44 (0)1865 283786

Fax: 44 (0)1865 374992

David Vaver MA BA LLB JD;

Professor of Intellectual Property \&

Information Technology Law, University of

Oxford

St Peter's College, Oxford OX1 2DL, UK Tel: 44 (0)865 278952

Fax: 44 (0)865 278959

E-mail: david.vaver@law.ox.ac.uk 